\title{
El triunfo y las crisis de la democracia liberal
}

\author{
Roberto RODRÍGUEZ GUERRA \\ Universidad de La Laguna \\ rrguerra@ull.es
}

Recibido: 13-04-2012

Aceptado: 09-10-2012

\begin{abstract}
Resumen
En el mismo momento en que se ha anunciado su definitivo triunfo asistimos, sin embargo y paradójicamente, a la constatación de la crisis de la democracia liberal. El presente trabajo, tras asumir que la democracia es hoy la forma de gobierno que goza de una amplia legitimidad y aceptación social, discute la veracidad y alcance empírico de la tesis del triunfo de la democracia liberal y vuelve sobre algunas de sus crisis a lo largo del siglo XX. A tal fin, recupera distintas y hasta contradictorias teorías de la crisis de tal forma de gobierno (en los años 20, en los años 70 y en la actualidad) para mostrar los serios y persistentes problemas que afronta la democracia liberal y concluye aportando unas pocas sugerencias para superar dichas crisis..
\end{abstract}

Palabras clave: Democratización; democracia liberal; parlamentarismo; crisis; representación; partidos; elecciones

\section{The Triumph and the Crises of Liberal Democracy}

\begin{abstract}
At the time of the announcement of its final triumph, we are however and paradoxically witnessing the crisis of liberal democracy. After assuming that democracy is nowadays the form of government that enjoys widespread legitimacy and social acceptance, this paper discusses the accuracy and the empirical scope of the thesis stating the triumph of liberal democracy. This paper looks back on some of the crises of liberal democracy during the twentieth century and retrieves different -and even contradictory- theories of the crises suffered in such form of government - in the 20's, 70's and today-. The final goal is to show the serious and persistent problems liberal democracy is facing and it concludes by providing suggestions to overcome these crises.
\end{abstract}

Key words: Democratization; liberal democracy; parlamentarism; crisis; representation; political parties; elections.

\section{Referencia normalizada}

Rodríguez Guerra, R. (2013). "El triunfo y las crisis de la democracia liberal”. Política y Sociedad, Vol.50, Núm. 2: Núm 2: 657-679

Sumario: Introducción. 1.Del ascenso de la democracia liberal. 2.De las crisis de la democracia liberal. 3.A modo de conclusión: y sin embargo hay alternativas. Bibliografía 


\section{Introducción}

El pasado siglo XX ha sido considerado como un «largo siglo de violencias» (Keane, 1996) o, acaso más acertadamente, como «la era de los extremos» (Hobsbawn, 1994). Pero, en lo que aquí nos interesa, también ha sido proclamado «el siglo de la democracia» (Freedom House, 2000). No obstante, bajo esta última proclamación hay quien en realidad no señale otra cosa que la idea comúnmente aceptada de que el siglo XX ha sido la etapa de la historia moderna en que la democracia ha alcanzado una amplia legitimidad y aceptación social. La democracia -se diría desde esta perspectiva- se ha quedado sin alternativas en tanto que su hegemonía es hoy indiscutible. Pero bajo aquella misma proclamación también suele afirmarse -como en los conocidos casos de Francis Fukuyama (1990: 6) y Giovanni Sartori (1991: 459)que si bien la democracia ha alcanzado tal legitimidad, lo cierto es que lo que realmente ha triunfado ha sido una de sus posibles formas y, por de pronto, aquella a la que -pese a sus plurales expresiones- hoy conocemos bajo la denominación de democracia liberal.

Tengo por cierto que la democracia posee hoy un alto grado de legitimidad. ${ }^{1} \mathrm{Pe}$ ro tengo igualmente por cierto que no ha ocurrido lo mismo con la «democracia liberal». Y no sólo porque ésta ha tenido un evidente lado oscuro (Mann, 2005), porque sus sendas hayan transcurrido entre la violencia y la globalización (Quesada, 2008) o, en fin, porque hoy sabemos no poco de las profundas desigualdades sociales, del aumento de la pobreza y de las situaciones de miseria y exclusión social que afectan a importantes sectores sociales, incluso en las sociedades desarrolladas y democrático-liberales. También porque su extensión empírica no es tan amplia como se suele dar a entender mediante la proclamación de su triunfo y porque, en el mismo momento en que, pese a todo, se ha anunciado su definitivo triunfo, asistimos, sin embargo y paradójicamente, a la constatación de su crisis ${ }^{2}$.

\footnotetext{
${ }^{1}$ Así, el Eurobarómetro para la Unión Europea 1997-1999 señala que el apoyo o la preferencia por la democracia en la Comunidad Europea alcanza el 78\% de los encuestados. Por su parte, el Latinobarómetro de 2011 indica que esta misma preferencia alcanza en la región la media del 58\% y supera el 70\% en los casos de Argentina, Uruguay y Venezuela. En la Europa del Sur (Portugal, Grecia, España e Italia) esa preferencia alcanzaba en 1985 el 61\% en Portugal, el 70\% en España e Italia y el 87\% en Grecia (Montero y Morlino, 1993). Para el caso de España véase la encuesta de opinión sobre la calidad de la democracia realizada en febrero-marzo de 2009 por el Centro de Investigaciones Sociológicas. Cf. también Montero, Gunther y Torcal (1999: 112), quienes por lo demás incluyen datos sobre la amplia preferibilidad de la democracia sobre otras formas de gobierno en España, Europa y algunos países latinoamericanos (Brasil, Chile, Uruguay Y Argentina).

${ }^{2}$ Si por crisis entendemos aquella situación en la que un sistema u organismo -a nuestros efectos la democracia liberal- se debate entre la vida y la muerte, creo por mi parte que, hoy por hoy, no es el caso de la democracia liberal. De ahí que, además de por su extendido
} 
Dando por sentada la veracidad del triunfo de la democracia o, más precisamente, el hecho de que la democracia es hoy la forma de gobierno que goza de una amplia legitimidad y aceptación social, en el presente trabajo discutiremos, en primer lugar, la veracidad y alcance del supuesto triunfo empírico de la democracia liberal y nos detendremos, en un segundo momento y acaso con mayor detalle, en varias de sus diferentes crisis a lo largo del siglo XX. No obstante, del ascenso y las crisis de la democracia liberal se viene hablando desde hace ya largo tiempo. De hecho, la aparición de diversas y hasta contradictorias teorías acerca de la crisis de la democracia liberal parece haberse convertido en un tópico en la reflexión teórica y en el debate político sobre tal forma de gobierno. Es seguro que esas crisis y reflexiones están alentadas por profundas transformaciones económicas, tecnológicas, culturales y sociales a las que aquí no podremos más que mencionar. Pero acaso ello se deba igualmente a que la democracia, como ya señalaban buena parte de los clásicos, es un régimen político notoriamente inestable y -ya lo sugería hacia principios del siglo XX Vilfredo Pareto (1985: 27)- en «continua mutación», esto es, constantemente obligado a adaptarse a las nuevas condiciones sociales y, con ello, a metamorfosearse de muy diferentes maneras.

Sea como fuere, lo cierto es que el debate en torno al ascenso y la crisis de la democracia liberal ha cobrado notable brío en diferentes momentos del pasado siglo XX. Aquí nos ocuparemos de tres de ellos y, concretamente, de aquellos que acaecieron en el momento de su inicio, de su auge y de su supuesto triunfo. De este modo, si, por un lado, ese debate surge en el mismo periodo en que la democracia liberal comienza a implantarse en diversos Estados, esto es, a principios del siglo $\mathrm{XX}$, por otro, cobra nueva actualidad en el periodo en que tal forma de gobierno se expande con cierto éxito, esto es, en los años 70 del pasado siglo, y resurge, finalmente, en el preciso instante en que se dice que tal forma de gobierno ha triunfado definitivamente, a saber, en la actualidad. Y puesto que tales debates iluminan la aparición y la persistencia de no pocos y persistentes problemas de la democracia liberal, acaso sea conveniente volver la mirada-siquiera sea de modo somero- sobre tales momentos, debates y problemas. Tal es el propósito de este trabajo en el que, tras remitirnos brevemente a la tesis acerca del ascenso y triunfo de la democracia liberal, retomaremos las citadas reflexiones acerca de sus crisis.

\section{Del ascenso de la democracia liberal}

La idea del ascenso o progresiva extensión de la democracia no es nueva. De hecho, esto era lo que ya sugería Tocqueville hacia mediados del siglo XIX cuando indicaba que La democracia en América (1963: 31) había sido escrita "bajo una preocu-

uso y hasta por economía de lenguaje, aquí utilice la noción de «crisis» de un modo más laxo y, concretamente, en el sentido de situación difícil o problemática. 
pación constante y un solo pensamiento: el advenimiento irresistible y universal de la Democracia en el mundo". Pero también lo afirmaba Max Weber (1991: 249) a principios del siglo XX al sostener que «el sistema de gobierno parlamentario» y la democratización del sufragio constituyen "un mandato de nuestro tiempo, necesario y políticamente inaplazable". En igual sentido se pronunciaba James Bryce (1921: 4), quien -pocos años después y en su conocido ensayo sobre las democracias modernas- daba cuenta de la tendencia a "la aceptación universal de la democracia como la forma natural y normal de gobierno". Nada de lo cual le impedía advertir acaso por la misma experiencia de la I Guerra Mundial, de la Revolución rusa y del incipiente ascenso del fascismo- la aparición de tendencias que podrían provocar «un proceso a la inversa». Ese mismo era, por último, el tenor de las reflexiones de Hans Kelsen, quién en Esencia y valor de la democracia (1988: 85) constataba el «lento pero irresistible progreso del movimiento democrático».

No obstante, aun partiendo de una mínima definición de la democracia liberal como aquella forma de gobierno en la que la elección de los representantes se realiza mediante sufragio universal, no cabe más remedio que reconocer que hacia principios del XX no existía ni una sola. Así lo afirman, por ejemplo, los redactores del ya citado Democracy's Century ${ }^{3}$. Pero no menos cierto es que -de recurrir al propio Bryce- tras el fin de la I Guerra Mundial y, en todo caso, hacia inicios de los años 20 del pasado siglo XX tan sólo existían 15.

En realidad, las esperanzas de Tocqueville, Weber, Kelsen o Bryce en torno al ascenso imparable de la democracia liberal tuvieron que esperar hasta mediados de siglo para encontrar cierto fundamento empírico. De hecho, no pocos estudios acerca de los procesos de democratización ${ }^{4}$ coinciden en señalar que la extensión de la democracia representativa tan solo ocurre -de manera aún limitada- tras el fin de la II Guerra Mundial ${ }^{5}$ y -ya de forma más amplia y sostenida- a partir de mediados de los 70 con las transiciones a la democracia en Portugal, España y Grecia.

Pero, aunque parten de diferentes definiciones de la democracia y poseen distintos énfasis que van desde un acrítico triunfalismo (Huntington, Freedom House) a un realismo más comedido (R. Dahl), coinciden igualmente en señalar que el avance de la democracia liberal ha sido más que significativo a lo largo del siglo XX. Expresado en los términos de Huntington (1994: 20), mientras que en 1973 existían 30 democracias (24,6\%), en 1990 el número de democracias asciende a 58 (el 45\%). Por su parte Robert Dahl (1999: 186) concluye que mientras en 1970 existían 40

\footnotetext{
${ }^{3}$ Informe sobre el proceso de expansión de la democracia en el mundo elaborado en el 2000 por Freedom House bajo la dirección de Francis Fukuyama, Seymour Martin Lipset, Orlando Patterson, Marc Plattner y Fareed Zakaria (http://www.freedomhouse.org).

${ }^{4}$ La gran mayoría de estos estudios se basan en concepciones procedimentales de la democracia sobre las que aquí no puedo detenerme. Me he ocupado de ellas en R. Rodríguez Guerra (2011).

${ }^{5}$ El ya citado estudio de Freedom House señala, por ejemplo, que hacia 1950 tan sólo existían 22 democracias (14\%) entre los 154 Estados por entonces existentes.
} 
poliarquías, en 1990 su número había ascendido a 65 (33,8\%), razón por la cual cree que -a diferencia de lo sugerido por Huntington- el citado triunfo de la democracia liberal ha de ser convenientemente matizado. Por último, el estudio de Larry Diamond (2008: 372)-que diferencia entre democracias electorales y democracia liberales- llega a la conclusión de que mientras en 1990 existían 81 democracias liberales (42,4\%) y 36 democracias electorales (18,8\%), en 2006 habría 78 democracias liberales (40,2\%) y 43 democracias electorales (22,1\%).

Ciertamente, de tales resultados puede concluirse que- si de la democracia liberal hablamos- ésta ha experimentado, desde comienzos del siglo XX hasta nuestros días, un considerable ascenso. Éste -que en modo alguno es lineal- va desde su inexistencia en 1900 hasta su presencia hacia principios del siglo XXI en 78 de los 194 Estados existentes. Pero lo que esto mismo nos indica es, en primer lugar, que, pese a tales avances, sobra el triunfalismo en torno a la extensión de la democracia liberal y, en segundo lugar, que no convendría confundir los ideales con las realidades ni, muchos menos, trasladar la legitimidad de aquellos a éstas. Para nuestro caso, que no convendría confundir la mayor o menor extensión o legitimidad de la democracia liberal con la legitimidad del ideal de democracia. Máxime cuando reparamos -como seguidamente veremos- en que la lenta expansión de la democracia liberal se ha visto acompañada por no pocos problemas y crisis.

\section{De las crisis de la democracia liberal}

No deja de ser inquietante que hoy, cuando muchas sociedades «periféricas» intentan liberarse de regímenes autoritarios y transitar hacia las democracias liberales de las sociedades desarrolladas, asistamos a la paradoja de que en estas mismas sociedades sea constatable un importante grado de descontento e insatisfacción hacia esa misma forma de gobierno. Pero -como decíamos al comienzo de estas páginasestos problemas vienen ya de lejos y, cuando menos, desde principios del siglo XX.

\subsection{De la crisis de la democracia liberal a principios del siglo $X X$}

No es este el momento ni el lugar para detenernos en el examen detallado de las condiciones a que se enfrentaban las sociedades de finales del XIX y principios del $\mathrm{XX}$. A nuestros efectos basta con indicar que se enfrentaron a un amplio conjunto de transformaciones que quizá puedan sintetizarse aludiendo las consecuencias de los procesos de racionalización, burocratización y oligarquización de diferentes ámbitos de la vida (Weber) o, en fin, del tránsito de la sociedad burguesa y el 
capitalismo liberal a la sociedad de masas y el capitalismo industrial ${ }^{6}$. $\mathrm{Y}$, en lo que aquí nos ocupa, no cabe duda de que la lucha por la ampliación de derechos políticos y por el sufragio universal, la emergencia de los partidos y sindicatos de masas, la progresiva burocratización y oligarquización de tales organizaciones, la creciente concentración y centralización del poder político, la progresiva importancia del liderazgo político o, en fin, la configuración de los partidos políticos como agentes imprescindibles de la dinámica política son algunas de esas importantes transformaciones políticas que incidirán de forma decisiva sobre la crisis de la democracia liberal en esta época.

Lo cierto es que tales cambios sociales y políticos, junto con la Primera Guerra Mundial y sus consecuencias, condujeron a la convicción de que los modos de organización política establecidos estaban experimentando serios problemas y desafíos y requerían en consecuencias importantes reformas. En tal sentido, el debate en torno a la crisis del parlamentarismo y la democracia liberal ocupó hacia la segunda década del siglo XX una posición nuclear. Y a fin de acercarnos a dicho debate aquí optaremos por una mirada crítica «desde el interior», esto es, por una aproximación a tal debate a partir de aquellas defensas — no exentas de críticaque de la democracia liberal realizaron precisamente quienes vislumbraron el ascenso del movimiento democrático y, particularmente, Kelsen y Weber.

Frente a la tesis de la «desintegración», «decadencia», «malestar» y hasta "crisis» de la democracia liberal defendidas desde posiciones bien diferentes por Carl Schmitt (1990) o Harold Laski (1935), Hans Kelsen sostuvo que si bien el parlamentarismo atravesaba por diversas dificultades, nada permitía sin embargo hablar de crisis, bancarrota o agonía del mismo.

Para Kelsen las indagaciones de Ostrogorski, Michels o Weber acerca de las características de la vida política y la democracia bajo las condiciones de la sociedad industrial y de masas aluden a la nueva realidad de que la democracia moderna dada la magnitud y la pluralidad de fines inherente a las sociedades modernasúnicamente puede ser una «democracia mediada, parlamentaria», esto es, una democracia "en la que la voluntad colectiva que prevalece es la determinada por la voluntad de la mayoría de aquellos que han sido elegidos por la mayoría de los ciudadanos”. Esta realidad exige para Kelsen el paso «de la libertad natural a la autodeterminación política mediante la decisión de la mayoría». Pero supone (Kelsen, 1977: 46) "la restricción del concepto ideal de pueblo al concepto mucho más

\footnotetext{
${ }^{6}$ En tal sentido, la creación de numerosas y gigantescas organizaciones empresariales y financieras, el desarrollo del capital monopolista, la internacionalización de la competencia económica o la creciente división en los procesos de organización del trabajo constituyen algunas las transformaciones que daban cuenta de las nuevas condiciones y circunstancias en que tal sociedad y economía habían de desenvolverse. Pero también lo fueron el auge del industrialismo, la creciente fragmentación y división social en clases y/o grupos que luchan por sus diferentes y hasta contradictorias intereses, el auge del movimiento obrero o, en fin, el incipiente reconocimiento de derechos sociales.
} 
limitado del conjunto de los titulares de derechos políticos, o, más bien, de los ejercientes de tales derechos". Al igual que también supone que "los derechos políticos -en los que consiste la libertad- se reducen en síntesis a un mero derecho de sufragio”. Así, frente a la asamblea de ciudadanos que participa de forma directa y cotidiana en la toma de decisiones políticas, la democracia moderna implica -y ello ha de ser reconocido abiertamente- una evidente restricción del ideal de autodeterminación y participación política. Pero no todo queda aquí, pues la democracia moderna no es sólo un régimen político que -como se desprende de lo señalado- ha de recurrir a la «ficción de la representación» (Kelsen, 1988: 88; 1983: 400). Es también, y está necesariamente abocada a serlo a menos que se imponga un modelo de representación corporativa o la dictadura, una «democracia de partidos».

Frente a las críticas de la izquierda y las propuestas «corporativas» de la derecha, la democracia moderna -sostiene Kelsen- "descansa sobre los partidos políticos”. Es más, requiere «un Estado de partidos» en tanto que éstos son las organizaciones que, en tal contexto, se sitúan entre el Estado y los individuos, agrupan a éstos a partir de fines políticos, contribuyen a la conformación de la voluntad y opinión política ciudadana y posibilitan su unión para influir eficazmente sobre la marcha de la vida pública. Quienes ven en los partidos un peligro para la unidad y tranquilidad del Estado -señala Kelsen (1977: 35) en evidente referencia a las posiciones de Carl Schmitt- tienen en realidad "una enemistad mal disimulada contra la democracia". Es más, como sostuviera Weber (1986: 128) en su conocida conferencia de 1919, frente a la dominación de los notables, "se alzan hoy abruptamente las más modernas formas de organización de los partidos [que] son hijas de la democracia, del derecho de las masas al sufragio, de la necesidad de hacer propaganda y organizaciones de masas y de la evolución hacia una dirección más unificada y una disciplina más rígida”. Puede que su propia existencia y su modo de funcionamiento sean en algunos aspectos moralmente censurables pero -añade Weber (1991: 132) - "lo que ya nadie podrá es eliminarlos por completo [...] so pena de eliminar a la vez toda forma activa de representación popular”.

Ahora bien, aunque los partidos políticos constituyen un elemento ineludible de la democracia moderna -hasta el punto de que Kelsen defiende su reconocimiento constitucional-, no es posible ignorar la realidad de su modo de funcionamiento. Refiriéndose expresamente a las sugerencias de Robert Michels, Kelsen reconoce que, aunque la inserción constitucional de los partidos en el Estado crea la posibilidad de democratizar el proceso de formación de la voluntad colectiva en el interior de los mismos, la realidad es que tal proceso posee un carácter señaladamente aristocrático-autoritario que desmiente tal posibilidad. De hecho, como señalaría por su parte Weber (1991: 132), estas organizaciones poseen una burocracia desarrollada que, puesta al servicio del «jefe de la máquina», no solo se encarga de las tareas políticas y administrativas necesarias para su funcionamiento. También elabora los programas, establece la táctica y hasta elige los candidatos. Como consecuencias de ello, los votantes y los propios miembros de los partidos no intervienen (o sólo lo hacen formalmente) en su vida política. En realidad, se limitan a pagar las cuotas, asistir a algunas reuniones y a votar cuando periódicamente se les 
convoca (1986: 139). Es más, al decir de Weber la lucha política bajo las condiciones de la democracia de masas tienden a convertir a los partidos en máquinas electorales guiadas por la única ratio de la boleta electoral, esto es, en organizaciones desprovistas de convicciones y cuyos "mutables programas son redactados para cada elección sin tener en cuenta otra cosa que la posibilidad de conquistar votos". En ello reside para Weber la evidente tendencia a la «desespiritualización» o «proletarización espiritual» de la actividad política partidista (1986: 150).

Pero la mutación de la democracia en «democracia de partidos» descansa, a su vez, sobre el parlamentarismo. Y sobre él cabe señalar -como una vez más reconoció expresamente Kelsen (1977: 47)- que "de todos los elementos mencionados hasta ahora como restrictivos de la idea liberal y, por tanto, de la democracia, el parlamentarismo es tal vez el más poderoso”. Es cierto que el recurso a la ficción de la representación se instituyó para "legalizar el parlamentarismo bajo el aspecto de la soberanía del pueblo" y para "ocultar la verdadera y esencial restricción que experimenta el principio de libertad por el parlamentarismo" (1988: 88; 1983: 400). Pero igualmente cierto es para Kelsen que éste puede ser justificado tanto por haber logrado mantener viva la fuerza del movimiento democrático cuanto porque en realidad constituye un medio para la estructuración de un orden estatal bajo las condiciones de la sociedad moderna y, particularmente, como respuesta a las exigencias de división del trabajo en tales sociedades. De ahí que Kelsen sostenga (1988: 87) que el parlamentarismo constituye en realidad un necesario "compromiso entre la exigencia democrática de libertad y el principio de división diferencial del trabajo que condiciona todo progreso de la técnica social”.

Kelsen es consciente -al igual que lo era Weber- de que el parlamentarismo experimentaba serios problemas ${ }^{3}$. Ahora bien, es sabido que sus soluciones serán bien diferentes. No es preciso insistir aquí en que Weber apuesta por consolidar el «giro cesarista» que a su modo ver experimenta la lucha política bajo la democracia de partidos. En tal sentido, convertir al Parlamento en órgano de "política positiva», que permita la lucha entre partidos y, en especial, la selección de auténticos líderes políticos constituye para él un objetivo de primer orden. Y ello porque cree que sólo los grandes líderes políticos, los grandes y carismáticos conductores de masas, son capaces de frenar o contrarrestar la creciente influencia de la burocracia y establecer verdaderos fines y objetivos políticos. Pero esto presupone -como explícitamente reconoce Weber (1986: 123 y 136)- dividir a los ciudadanos "en elementos políticamente activos y políticamente pasivos", así como convertir a casi todos los miembros del Parlamento en "unos borregos votantes perfectamente disciplinados". La democratización -sostiene Weber- no significará "necesariamente el aumento de la participación activa de los dominados en el dominio". Es más, cree (1984: 739)

${ }^{7}$ Un buen resumen de los mismos, aunque obviamente desde sus posiciones, pude verse en las reflexiones de Carl Schmitt sobre la situación histórico espiritual del parlamentarismo (1990, 24). 
que el demos "no gobierna nunca por sí mismo en las sociedades numerosas, sino que es «gobernado", cambiando sólo la forma de selección de los jefes del gobierno y la proporción de la influencia que puede ejercer, o mejor dicho, que pueden ejercer otros círculos procedentes de su seno, por medio del complemento de una llamada «opinión pública» sobre el contenido y la dirección de la actividad del gobierno".

Diferente será sin embargo, la propuesta de Kelsen. Éste creía que los problemas del parlamentarismo podían ser paliados a través de una reforma del mismo. Ésta debía alejarse de aquella errónea idea de que sólo a través del parlamentarismo puede expresarse la voluntad popular y, por ello mismo, apostar por "intensificar sus elementos democráticos” (1977: 52 y 64). En tal sentido son conocidas sus propuestas de preservar el principio de la mayoría «que presupone el derecho de existencia [y la protección] de una minoría», eliminar las prácticas parlamentarias obstruccionistas,... Pero también de instaurar el sufragio universal, institucionalizar el referéndum constitucional y legislativo, regular la iniciativa legislativa popular, reducir o abolir la irresponsabilidad de los diputados acogida bajo el concepto de inmunidad, instituir la revocación de los parlamentarios, establecer sistemas electorales proporcionales o, finalmente, descentralizar el poder político.

No obstante, las esperanzas y posibilidades que sugiere Kelsen encontraron poca cabida en las posteriores transformaciones de la democracia. De hecho, habida cuenta de la intensificación de las tendencias oligárquicas y elitistas de la vida política en las sociedades complejas, podría decirse que es Weber y no Kelsen quien realmente triunfa. Eso es lo que sin duda refleja la creciente influencia que, tras la estela de Weber, cobraron las posteriores teorías elitistas de la democracia ${ }^{8}$. Sin embargo y más allá de algunas reflexiones aisladas, habría que esperar aún dos décadas más, esto es, a principios de los años 70 para constatar la emergencia de nuevas y bien diferentes teorías de la crisis de la democracia liberal.

La primera de ellas se articula en torno a la crítica de los «excesos» e «ingobernabilidad» de la democracia y la propuesta de retorno a formas decididamente elitistas de democracia. En ellas las tesis de Crozier, Huntington y Watanuki son sin duda germinales y profundamente significativas. La segunda está representada por aquella crítica de las insuficiencias de la democracia liberal y la apuesta por un «enfoque participativo». Las aportaciones de Carole Pateman y Crawford Macpherson son de las más relevantes a este respecto.

${ }^{8}$ De estas diferentes teorías he tenido ocasión de ocuparme en R. Rodríguez Guerra (1998, cap. IV) 


\subsection{La crisis de la democracia liberal desde el enfoque restrictivo}

El enfoque restrictivo surge básicamente tras el fin de la época de bonanza económica y, particularmente, a raíz de la crisis iniciada hacia 1973. La profundidad y larga duración de dicha crisis supuso el estancamiento del crecimiento económico, situaciones de desempleo masivo, la reducción de las prestaciones sociales, el recrudecimiento de las tensiones socio-laborales y políticas, la pérdida de la paz social y el fin de la «edad de oro del capitalismo». Incluso parece haber sido también el origen de lo que Daniel Bell (1977: 39) considera como «crisis cultural». Es en este contexto en el que, en 1975, M. Crozier, S. P. Huntington y J. Watanuki redactaron el conocido Report on the Governability of Democracies y formularon buena parte de las tesis básicas de las teorías de la ingobernabilidad. En dicho Informe se sostenía que en el periodo posterior a la II Guerra Mundial se había desarrollado una «cultura adversaria» (Trilling, 1965: 12) que alentó «una década de efervescencia democrática y de reafirmación del igualitarismo democrático» que, a su vez, sembraron una creciente desconfianza hacia la democracia liberal y sus instituciones políticas (Crozier, Huntington y Watanuki, 1975: 60). En su opinión tal exceso de democracia y de igualitarismo suponían la aparición de un serio desafío a la propia democracia liberal en tanto que daban carta de naturaleza (Crozier, Huntington y Watanuki, 1975: 8) a "fuerzas y tendencias que, libres de la restricción de otras instancias externas, conducirán a la ruina de la propia democracia". El desarrollo de aquella «cultura adversaria» había generado -al decir de estos autores- una pérdida de confianza en el liderazgo y la autoridad (familiar, sexual, grupal, política). Pero también la creciente politización de una ciudadanía que, en nombre de dicho igualitarismo, presentaba crecientes demandas al Estado. Es así como surgieron (Brittan, 1975: 141) las «contradicciones internas» de una democracia liberal que daba "a las expectativas un sesgo sistemáticamente ascendente" o que conducía a «una revolución de los títulos en ascenso», esto es, a que grupos y ciudadanos aumentasen sus "demandas de protección y derechos, en resumen, de títulos" (Bell, 1977: 220). El resultado conducía a la «sobrecarga» del gobierno a causa de un conjunto de demandas que éste, dado su nivel decreciente de recursos, supuestamente no podía satisfacer. Y todo ello habría generado, por último, una creciente desconfianza ciudadana con el gobierno y la autoridad establecida, una progresiva pérdida de fe en el liderazgo político y en el propio sistema de partidos y, finalmente, el desencanto de los ciudadanos con las instituciones de la democracia liberal.

Al decir de Friedrich von Hayek (1976: 32) el resultado de esta «mecánica democrática» se resume en el hecho de que, lejos de plasmar la voluntad de la mayoría, cualquier reducido grupo de intereses tiene una amplia capacidad para "imponer sus particulares pretensiones sobre el resto de la sociedad, no sobre la base de persuadir a la mayoría en cuanto a la justicia o equidad de las mismas, sino apelando simplemente a la amenaza de retirar su apoyo a los grupos que, sin él, no pueden disponer del respaldo mayoritario que precisan”. Pero esa misma «mecánica» conduce, además, al predominio de la burocracia, a la omnipotencia estatal y a un 
creciente déficit presupuestario que-dicho ahora en términos de James Buchanan y Richard Wagner (1977) - no es más que la expresión de la «natural» proclividad de la democracia a generar déficits. En tales circunstancias puede aceptarse -sugieren Crozier, Huntington y Watanuki- que la democracia continuará operando pero, eso sí, en franca crisis y deterioro.

Puesto que la democracia y el igualitarismo son los culpables, la solución estriba en que tanto una como otro retrocedan. Las terapias concretas a este respecto son las conocidas recetas neoliberales, hoy tan en boga. En lo que aquí nos ocupa, pasan, en primer lugar, por la despolitización del ciudadano, la reducción de sus posibilidades de participación política y la limitación de la democracia. El equilibrio entre la democracia y la gobernabilidad no requiere que apliquemos la receta según la cual la única cura para los males de la democracia es más democracia. Esto indican los redactores del Informe- no sería más «que echar leña al fuego». Lo que se requiere es, por el contrario, «un enorme grado de moderación en la democracia». Y esto significa (Crozier, Huntington y Watanuki, 1975: 113) que los ciudadanos han de aceptar, por una parte, que "los ámbitos donde los procedimientos democráticos son apropiados son escasos" y, por otra, que "el desenvolvimiento efectivo de un sistema político democrático usualmente requiere cierto grado de apatía y descompromiso por parte de algunos individuos y grupos". Y será preciso, en segundo lugar, fortalecer las instituciones de liderazgo político (presidencialismo), revitalizar los partidos políticos (ayudas económicas) o restaurar el equilibrio entre el gobierno y los medios de comunicación (cierto control sobre la libertad de prensa). Pero también, por último, revitalizar valores como la disciplina, el trabajo, la propiedad e iniciativa privada o la caridad, recuperar instituciones intermedias como la religión, la familia o las asociaciones voluntarias, volver a la religión fiscal de los viejos tiempos e instaurar el principio del equilibrio presupuestario, privatizar gran parte de los servicios públicos y, en fin, articular una precisa definición de los derechos individuales y, especialmente, de los derechos de propiedad (Crozier, Huntington y Watanuki, 1975: 173). En suma, el enfoque restrictivo nos sitúa ante una estrecha y elitista concepción de lo político y la política guiada por la exigencia de apatía y descompromiso ciudadano, así como por la drástica reducción de los derechos políticos y sociales de la ciudadanía. Y ha sido precisamente esta propuesta neoliberal la que, más de tres décadas después, sigue marcando nuestros destinos y la actual crisis de la democracia liberal. Pero antes de abordar esta última, hemos de acercarnos a las ya mencionadas teorías acerca de la crisis de la democracia liberal desde el enfoque participativo.

\subsection{La crisis de la democracia liberal desde el enfoque participativo}

La afirmación de Crozier, Huntington y Watanuki acerca de la emergencia, en el periodo posterior a la II Guerra Mundial, de cierto grado de efervescencia democrática y de igualitarismo socio-político respondían en realidad a la aparición y consolidación de una diversidad de movimientos (derechos civiles y políticos, estudiantil, 
feminista, ecologista, pacifista). Estos plantearon la necesidad de democratizar el Estado, en primer lugar, procediendo a la «apertura de nuevas áreas de participación» y a «la implementación práctica de derechos de participación» que al menos en teoría eran propios de los ciudadanos y, en segundo lugar, haciendo a los representantes, a los parlamentos y a los partidos políticos más accesibles a (y responsables ante) los ciudadanos. Lograron así -como sostiene Macpherson (1987: 1 y 113)- no sólo que el concepto "participación» pasara formar parte del vocabulario popular. También consiguieron extender considerablemente "la idea de que debería haber una participación considerable de los ciudadanos en la formulación de las decisiones por el gobierno“. Y lo hacían porque sabían de las insuficiencias de las instituciones tradicionales de la democracia representativa (procesos electorales, partidos políticos y parlamentarismo) y, particularmente, de la acentuación de las tendencias oligárquicas y «desepiritualizadoras» en el interior de unos partidos quesegún la conocida expresión de Otto Kirchheimer (1954 y 1980)- se habían convertido en «partidos atrapalotodo». De hecho, tales demandas surgen de la conciencia de que el sistema político vigente era «no participativo o apenas participativo» y con la explícita intención de someter a crítica aquella forma de participación que en opinión de Macpherson (1987: 119)- representaba "la competencia oligopólica de partidos políticos prevalente entre nosotros, que no sólo no es muy participativa, sino que es acuñada por la mayor parte de los teóricos de la democracia liberal como la quintaesencia no participativa”.

Es probable que tanto el alejamiento de los cauces políticos tradicionales como la demanda de otras formas de participación estuvieran relacionados con aquella «revolución silenciosa» que, al decir de Ronald Inglehart (1977), expresaba un cambio gradual y persistente en las prioridades valorativas de amplios sectores de las sociedades occidentales. Un cambio por el cual los valores «postmateriales» (autonomía, autoexpresión, libertad personal, sentimiento de pertenencia a la comunidad, calidad de vida o mayor y mejor participación) cobran especial relevancia y conducen a la alteración de los temas políticos conflictivos (paz, medioambiente, sexualidad,...), a un cambio en las bases sociales del conflicto (declive relativo de los conflictos de clase), a un descenso de la lealtad hacia las instituciones y autoridades tradicionales (familia, religión,...) y al uso de otras formas de participación y movilización políticas (declive de las formas convencionales y dirigidas por las élites y ascenso de las formas alternativas e informales) que conllevaba un declive gradual de la militancia en (y la cercanía a) los partidos políticos (Inglehart, 1991: 401).

Tales movimientos y protestas supusieron la emergencia de un "pluralismo social o asociativo» (R. Rodríguez Guerra, 1998a: 69-97) que en mayor o menor medida siempre había estado presente pero que ahora - por decirlo con Claus Offe (1988: 163)- surge como un conjunto de «nuevos movimientos sociales» que constituyen la expresión práctica de un «nuevo paradigma» político que cobra expresión teórica en las teorías de la democracia participativa.

El enfoque participativo pretende situar el problema de la participación política y su rol en la teoría de la democracia "en un contexto más amplio que el proporciona- 
do por la teoría contemporánea de la democracia" (Pateman, 2000: 111). Con tal propósito parte del principio de que "la existencia de instituciones representativas a nivel nacional no es suficiente para la democracia". Ésta debe ser implantada "en otras esferas a fin de que las necesarias actitudes individuales y cualidades psicológicas puedan ser desarrolladas”. Un desarrollo que podría transcurrir adecuadamente a través de variados "procesos de participación» (Pateman, 2000: 42). La justificación de esta demanda de procesos participativos descansa pues -como aduce Pateman- "en los resultados humanos que se derivan del proceso participativo", esto es, en que tal proceso fomenta del desarrollo de las capacidades de cada individuo, mejora el sentimiento de eficacia política, reduce la alienación respecto de los poderes establecidos, aumenta la preocupación por los problemas colectivos y, en suma, contribuye a la formación de una ciudadanía activa y preocupada por su comunidad $^{9}$.

Pero una política realmente participativa requiere -al decir de Pateman o Macpherson- una sociedad participativa, es decir, "una sociedad en la que todos los sistemas políticos hayan sido democratizados y la socialización a través de la participación pueda tener lugar en todas las áreas" (Macpherson, 1987: 119). De ahí que el enfoque participativo persiga extender la democracia más allá del Estado y sus instituciones políticas habituales y llevarla a otros ámbitos sociales. Propone por tanto una amplia definición de «lo político» (Bachrach, 1973: 158) y vuelve su mirada hacia las posibilidades y las experiencias de participación política en el lugar de trabajo, en los barrios o, en suma, en la esfera de la sociedad civil (Pateman, 2000, caps. II, IV y V; Macpherson, 1987: 125).

Pese a que centraron su atención en la apertura de cauces de participación en los ámbitos locales o próximos al ciudadano, los proponentes del enfoque participativo también aportaron algunas sugerencias respecto de posibles modelos de democracia participativa. Acaso conscientes de lo que posteriormente Norberto Bobbio (1984 y 1985: 25) denominó las «paradojas» y «promesas incumplidas de la democracia» ${ }^{10}$, reconocieron que en las complejas sociedades desarrolladas las elecciones, los partidos políticos y el propio sistema representativo seguían siendo necesarios. De hecho, pese a sus posibilidades, ni el referéndum ni las oportunidades que a tal efecto ofrecen las nuevas tecnologías de la comunicación se consideraban por entonces «la solución» a la crisis de la democracia liberal (Pateman, 2000: 109; Macpherson, 1987: 118; Bobbio, 1986: 104). De ahí que concibieran la democracia participativa como combinación entre elementos de la democracia representativa y

\footnotetext{
${ }^{9}$ En este mismo sentido se había pronunciado años antes, en 1967, Peter Bachrach (1973: 157).

${ }^{10}$ Una primera formulación, de 1973, de la noción de «promesas incumplidas de la democracia» la desarrollo Bobbio en “¿Democracia socialista?” (Bobbio, 1986).
} 
de la democracia directa ${ }^{11}$. Macpherson propuso en tal sentido la «combinación» de un mecanismo democrático directo/indirecto de carácter «piramidal» (democracia de base y delegada en la cúspide) con un sistema de partidos competitivos que, no obstante, habrían de ser «auténticamente participativos», esto es, "funcionar por participación piramidal". De ser así tampoco habría mayor problema en que formasen parte de alguna estructura parlamentaria complementada y controlada por la democracia directa propia de los ámbitos de base. Y un modelo de estas características -concluye Macpherson (1987: 137)- podría ser considerado como una forma de democracia liberal, pues su garantía no estriba tanto en la necesidad de los partidos políticos cuanto en la existencia de "un sentimiento vigoroso y generalizado del valor del principio ético democrático-liberal [de] la igualdad del derecho de todos los hombres y todas las mujeres al pleno desarrollo y uso de sus capacidades".

Pero, como se verá en lo que sigue, las esperanzas y propuestas del enfoque participativo parecen haber sido abiertamente negadas por la realidad de la crisis de la democracia liberal en nuestros días.

\subsection{De la actual crisis de la democracia liberal}

Un mínimo intento de acercamiento a los problemas actuales de la democracia liberal debe comenzar señalando que los fenómenos sociales de las últimas décadas nos sitúan, nuevamente, ante una época marcada por importantes transformaciones generalmente asociadas con la globalización. En efecto, fenómenos tales como la liberalización «condicionada» de la circulación de mercancías, «selectiva» de los movimientos de personas y «absoluta» de los flujos financieros, los procesos de concentración oligopólica de los poderes económicos o el inmenso y acelerado desarrollo de las tecnologías de la información y la comunicación reflejan algunos de los decisivos cambios que nuestras sociedades han experimentado. Pero también lo son la progresiva creación y extensión -en especial a partir de mediados del pasado siglo XX- de múltiples entidades de carácter mundial (ONU, UNESCO,..), interestatal (UE, OTAN, MERCOSUR, CELAC,..) o grupos interestatales informales (G7, G8, G20) que han asumido -de hecho o de derecho- la capacidad de adoptar múltiples decisiones políticas otrora consideradas propias del Estado nacional. Como también la tienen muchas otras entidades (FMI, BM, OMC) que de hecho han cobrado un papel trascendental en la determinación de políticas que poseen una enorme influencia sobre nuestras vidas y que -una vez más- intervienen decisiva-

11 "Parece evidente -señalaba por su parte Macpherson (1987: 115 y 118)- que, a nivel nacional, será necesario disponer de algún tipo de sistema representativo, y no de una democracia completamente directa... No podemos prescindir de los políticos elegidos. Debemos utilizar la democracia indirecta, aunque no hace falta utilizarla en exclusiva”. 
mente sobre las decisiones de los Estados y sus respectivos gobiernos ${ }^{12}$. Por último, es igualmente relevante la enorme capacidad de «presión» que las potencias hegemónicas ejercen sobre otros Estados -especialmente, aunque no sólo, sobre los Estados pobres- a fin de imponer políticas e incluso -como muestran los casos reciente de Grecia e Italia- gobiernos. Ninguno de estos fenómenos es plenamente reciente o novedoso, pero parece indudable que se han intensificado en las últimas décadas.

A partir de tales procesos es evidente que los principios de soberanía popular y soberanía nacional están hoy más que debilitados. Muchas decisiones políticas que afectan decisivamente a nuestras vidas son tomadas actualmente por organizaciones supranacionales que, aún bajo parámetros flexibles, adolecen de serios déficits democráticos. Pese a que los Estados sigan poseyendo un amplio e importante conjunto de capacidades para determinar nuestras vidas, lo cierto es que hoy es notorio que el Estado nacional no es ya aquella entidad que ostenta el monopolio del uso legítimo de la fuerza. Como tampoco ostenta el monopolio de la elaboración y aprobación de las políticas que afectan a nuestras vidas. Ni ostenta, por último, el monopolio legislativo o de creación de derecho (Held, 2001: 383). De ahí que, bajo tales condiciones, aquella relación de congruencia que la democracia liberal presupone entre poder político y pueblo, entre representantes y representados o, en fin, entre gobernantes y gobernados haya quebrado en sustanciales aspectos.

Pero esta misma quiebra se ve especialmente agudizada por el impresionante desarrollo de una diversidad de gigantescos grupos económicos de distinto tipo (empresariales, mediáticos, financieros) y de alcance internacional que poseen múltiples y poderosos recursos (inversión, desinversión, deslocalización, compra/venta de bonos, movilización de descomunales recursos financieros, control de los medios de comunicación) para «orientar» o incluso determinar las decisiones de los poderes políticos democráticamente establecidos. De hecho, la inserción de estos poderosos grupos privados en un sistema económico globalizado carente de adecuados frenos y regulaciones ha supuesto un proceso de concentración oligopólica del poder económico que igualmente amenaza la capacidad de los Estados y gobiernos nacionales -e incluso la de las organizaciones regionales e internacionales- para dirigir autónomamente los destinos de su comunidad de referencia. Nada de extraño tiene pues que hoy pueda hablarse de una «democracia dirigida» (Wolin, 2000), del «invierno de la democracia» (Hermet, 2008) o, incluso, de una "regresión neoabsolutista tanto de las grandes potencias como de los grandes poderes económicos globales” (Ferrajoli, 2011a: 516). Hasta tal punto es así que -como añade el propio Ferrajoli (2011: 517)- hoy es común la idea de que "ya no es la política la que gobierna y controla la economía, sino ésta la que gobierna aquélla”.

${ }^{12}$ Según indica David Held (1997: 139) mientras en 1909 había 37 OIG [Organizaciones Intergubernamentales] y 176 ONGI (Organizaciones no Gubernamentales Internacionales) en 1989 las OIG eran casi 300 y las ONGI 4.624. 
Sin embargo, el «triunfo de la economía» acaso no sea en realidad más que un trasunto del «triunfo de la política» o, concretamente, de ciertas políticas y, por de pronto, de aquellas a las que hoy reconocemos bajo el rótulo de políticas neoliberales (J. Rodríguez Guerra, 2001: 185) ${ }^{13}$. Todos estos fenómenos son constitutivos de la actual crisis de la democracia liberal que se revela igualmente a través de otros hechos. Y acaso uno de los más relevantes sea la preocupante emergencia -en las mismas sociedades democráticas desarrolladas- de evidentes manifestaciones de «desafección democrática» (Offe, 2001; Torcal, 2001). Aunque en ellas es constatable -como ya se sugirió en los inicios de este trabajo- un amplio grado de confianza y preferencia por la democracia frente a otras formas de gobierno, no menos cierto es que en tales sociedades existen porcentajes significativos de insatisfacción con el funcionamiento de la democracia liberal, de abstención electoral, de pérdida de confianza en las instituciones, de alejamiento de los procedimientos institucionalizados de participación política o, en fin, de conductas y comportamientos políticos negativos hacia la política y los políticos. Es muy probable que estas actitudes y percepciones estén directamente relacionadas con las circunstancias más arriba señaladas. Pero me temo que mucho tienen que ver también con el funcionamiento de la misma democracia liberal y de algunos de sus cauces clásicos de participación política $^{14}$.

Particularmente relevante en este último sentido es la creciente crisis que afecta a los partidos políticos, esto es, a aquellas instituciones que desde hace ya más de un siglo han sido concebidas como los cauces fundamentales de representación, mediación y participación políticas. Si el partido «atrapalotodo» fue el modelo de partido predominante en los años de posteriores a la II Guerra Mundial, hacia finales del siglo XX lo sería una versión intensificada del mismo: el "partido cartel» (Katz y Mair, 2004). Éste se caracteriza por una escasa dependencia de su base militante, la reducción de sus perfiles ideológicos, la personalización de la imagen del partido y de su política en líderes locales y nacionales, la constante realización de campañas electorales centralizadas, profesionalizadas y costosas, el manejo y contención de la competencia política sobre la base del acuerdo interpartidista de reparto de escaños, cargos, etc., y, sobre todo, por su amplísima dependencia de las subvenciones de parte del Estado y de las empresas o grupos económicos. El tan viejo como actual problema de la corrupción en los partidos es sin duda sintomático de esto último.

${ }^{13}$ Es ya un lugar común reconocer que las políticas neoliberales, pese a sus evidentes expresiones teóricas en la obra de autores como el citado Hayek o Milton Friedman, cobran clara expresión práctica a través del decálogo de reformas políticas (desregulación, privatización, liberalización, disciplina presupuestaria, reforma fiscal, protección de la propiedad privada,...) inicialmente formulado por John Williamson ("What Washington Means by Policy Reform", 1989) y hoy conocido como el «Consenso de Washington».

${ }^{14}$ Para el caso de España véase Justino Sinova y Javier Tusell (1997). Para el caso de Italia Luigi Ferrajoli (2011b). 
Ahora bien, si tal es la realidad de aquellos instrumentos que -como decíamoshan sido llamados a convertirse tanto en el cauce fundamental de participación y representación políticas como en el medio de re-presentar parlamentariamente la voluntad y opinión política ciudadana, pocas dudas cabe de que la misma democracia liberal adolece serios déficits de participación y credibilidad. De hecho parece haberse reducido -como quería Schumpeter- a una mera lucha entre élites políticas por el voto del pueblo o a la posibilidad de que los votantes puedan elegir entre un menú considerablemente reducido y estable de partidos. Una percepción que, sin duda, se agudiza aún más cuando constatamos que las campañas electorales son poco más que un espectáculo mediático con escaso contenido programático, orientado por los parámetros del marketing electoral y organizado por los expertos en la mercadotecnia política ${ }^{15}$ y en el manejo de las redes de comunicación social. En ellas, las ofertas electorales se parecen cada vez más, se debate sobre personas/candidatos y -cuando es el caso- sobre fines generales ampliamente compartidos, pero no sobre programas y políticas alternativas. De ahí que hoy nos refiramos a la democracia liberal como una «democracia de audiencia» (Manin, 1998: 267) guiada por la personalización de la oferta electoral, orientada por los estudios de opinión y las encuestas electorales, marcada por el imperio de la imagen y necesitada de ingentes recursos económicos. Y son precisamente estos hechos los que han conducido -por decirlo con Ferrajoli (2001b: 53)- a que en las democracias establecidas sea "cada vez más fuerte la relación entre dinero, información y política: dinero para hacer política e información, información para hacer dinero y política, política para hacer dinero e información, según un círculo vicioso que se resuelve en el creciente condicionamiento anti- o extra-representativo de la acción de gobierno".

Pero igualmente relevante de los problemas de las actuales democracias liberales es la ya larga y profunda crisis del parlamentarismo. Pese a la retórica en torno a su carácter de institución fundamental de la democracia liberal, los Parlamentos han quedado reducidos a órganos que sirven de correa de transmisión y caja de resonancia del poder ejecutivo y, particularmente, del presidente o primer ministro (y su equipo). De hecho, sus sesiones se han convertido en un puro trámite, en una escenificación -convenientemente jaleada o abucheada- de decisiones previamente tomadas. Y esto es aún más grave en cuanto nos percatamos del escaso poder de iniciativa y control que tiene la oposición, de la marginación de las minorías de la oposición, de los privilegios reglamentarios de que goza el ejecutivo o, en fin, de la enorme capacidad de «gobernar por decreto» de que éste dispone.

Esta última tendencia nos remite a su vez a la creciente transformación y degradación de las actuales democracia liberales en «democracias delegativas» o, cuando

${ }^{15}$ Para un acercamiento crítico a las estrategias, fines y medios de la mercadotecnia política desde la perspectiva de la actual hegemonía de la imagen en las democracias actuales véase, entre otros muchos, J.C. Acinas (2009) 
menos, "presidencialistas», esto es, a aquel nuevo animal sobre el que Guillermo O’Donnel (1997) ha llamado la atención a raíz de la concentración de poderes en manos del ejecutivo y a la reducción o marginación de las instituciones y procedimientos de control y rendición de cuentas. Y esto último se complementa, finalmente, con la extendida pérdida del sentido de la responsabilidad política y su remisión a los resultados de las procedentes resoluciones judiciales, esto es, a la responsabilidad jurídica.

Sin duda, existen otros factores que están contribuyendo actualmente a la crisis de la democracia liberal. Pero los límites de este trabajo aconsejan que me ciña a una última cuestión que -al menos a mí entender- resulta de especial importancia: los sistemas electorales mayoritarios o proporcionales «corregidos». Tales sistemas son bipartidistas o tendencialmente bipartidistas, con lo cual reducen significativamente la expresión política de la pluralidad social subyacente. Pero por ello mismo son beneficiosos para las opciones mayoritarias y perjudiciales para las minoritarias. En tanto que otorgan a las opciones mayoritarias una representación superior a la que en pura proporcionalidad les corresponde y a las opciones minoritarias una inferior a la que deberían obtener, conducen en realidad a una apropiación ilegítima de escaños y, por consiguiente, a una desposesión igualmente ilegítima de escaños. Y esto, además de las muchas consecuencias que tiene para la actividad política, no es más que una seria distorsión de la representación o, en suma, un evidente déficit de representación.

\section{A modo de conclusión: y sin embargo hay alternativas}

$\mathrm{Si}$, a modo de conclusión, me viese obligado a sintetizar de alguna forma los problemas actuales de la democracia liberal, diría por mi parte que éstos se resumen en sus crisis de soberanía, representación, participación y credibilidad. No parece sin embargo que, al menos por al momento, tales crisis sitúen a la democracia liberal en vías de extinción. Ciertamente no nos encontramos, como en la segunda y tercera década del pasado siglo, ante la posibilidad de su generalizada sustitución por otros sistemas políticos comunistas o fascistas. Tampoco nos encontramos, como ocurría en los años 70, ante la alternativa real de un sistema ideológico, económico y político alternativo. No obstante, finalizada la guerra fría y desmoronado el socialismo real, no son pocas las democracias liberales que afrontan un serio proceso de deterioro y degradación, hasta el punto de que algunas derivan hacia meras «democracias electorales» o, incluso, hacia ciertas formas de autoritarismo electoral (Wigell, 2008: 244).

Ciertamente, las alternativas a la actual crisis de la democracia liberal tropiezan con no pocas dificultades teóricas y prácticas. Pero las crisis nada tienen de «natural» o de «destino inevitable». Son producto de tendencias auspiciadas por fuerzas sociales, esto es, son fruto de determinadas opciones políticas frente a las que, sin duda, existen alternativas. Por mi parte creo que estas otras opciones políticas han de alejarse de las actuales tendencias neoliberales de aniquilación de la política y la 
remercantilización de las diferentes esferas de la sociedad. Deberían, por el contrario, construirse a partir de una repotenciación de la política y, por de pronto, a través de una respuesta de carácter democrático y social.

Pero, dada la realidad de un mundo globalizado, creo que esas alternativas democratizadoras han de desarrollarse tanto a nivel local como a nivel estatal, interestatal y global. Es más, creo que su primera tarea ha de afrontar la necesidad de civilizar y someter a control público y democrático los «poderes salvajes».

En tal sentido, creo que, si bien es preciso un sano cosmoescepticismo políticogubernamental y hasta un prudente euroescepticismo ${ }^{16}$, el desarrollo de ciertos principios cosmopolitas y de un derecho democrático cosmopolita (Held, 2011: 75 y 102) podría considerarse una tarea primordial ${ }^{17}$. Un orden y un derecho de este tipo, constitucionalmente articulados y garantizados, habrían de estar situados por encima tanto de las legislaciones estatales y de los diversos organismos regionales e internacionales cuanto de los poderes salvajes. En este mismo sentido, el desarrollo de organismos regionales como la Unión Europea podría igualmente considerarse de especial importancia, si bien en modo alguno cabe ocultar la imperiosa necesidad de subsanar sus evidentes déficits constitucionales, democráticos y sociales (Habermas, 2000: 118; 2004: 91). Cosa bien distinta es la traducción de aquel cosmopolitismo en una suerte de Estado y gobierno mundial (Habermas, 2000: 136), aunque ello fuese sobre la base de una supuesta democracia igualmente mundial. Hoy sabemos de los enormes peligros que habría de afrontar tal posibilidad ${ }^{18}$, el menor de los cuales no sería - de ahí buena parte del escepticismo políticogubernamental antes comentado- el de la creación de estructuras o burocracias mundiales sumamente alejadas de los ciudadanos, débilmente responsable ante éstos y muy permeables por ello a la influencia de los «poderes salvajes». Por lo demás, la participación política de los ciudadanos en (y a través de) esas estructuras u organismos mundiales o incluso interestatales ha de ser necesariamente escasa y

\footnotetext{
${ }^{16}$ Ese escepticismo vendría fundado -por decirlo con Javier Muguerza (2004: 83)- en la idea de que "ni está claro por ahora que el cosmos sea una pólis, es decir, una sociedad cuyos miembros sean ciudadanos de un «Mundo-Estado» o Estado mundial (cosa bastante más indeseable, siquiera sea en las actuales circunstancias, de lo que hayan podido serlo en el pasado sus predecesoras la Ciudad-Estado o la Nación-Estado), ni mucho menos se halla a nuestro alcance la posibilidad de una utópica pólis sin politéia, esto es, de una «ciudadanía sin Estado» que nos permita proclamarnos «ciudadanos del mundo», como no sea por el momento sino a título puramente retórico". A lo cual añadiría -con Robert Dahl 2004, 530 y s.- que las decisiones políticas de la organizaciones internacionales no serán tomadas habitualmente de forma democrática, además de que las posibilidades de que los ciudadanos tengan algún grado de control e influencia sobre tales decisiones son en verdad escasas.

${ }^{17}$ Un buen acercamiento al debate y posiciones en torno al proyecto cosmopolita puede encontrarse en Danielle Archibugi (2005). Entre nosotros véase también Javier Peña (2010).

${ }^{18}$ Para un rápido acercamiento a tales dificultades véase Ernesto Garzón Valdés (2003: 22-31) y Danilo Zolo (2000).
} 
limitada, de hecho, a la elección periódica de representantes y a la posible articulación de una opinión pública global o europea. De ahí que crea con Ferrajoli que lo que hoy necesitamos no sean tanto instituciones o funciones globales de gobierno que habrían de articularse en lo posible en el ámbito estatal y sus comunidades subestatales- cuanto "funciones e instituciones de garantías, vinculadas a las garantías de los derechos fundamentales". En tal sentido, la Carta de la ONU de 1945, las Declaración Universal de Derechos Humanos de 1948 y los Pactos de derechos civiles, políticos económicos y culturales de 1966 podrían tomarse como un excelente punto de partida para una posible constitución mundial. Cosa bien distinta es que en la práctica casi se hayan quedado en papel mojado o en un nuevo conjunto de «promesas incumplidas». Como también lo es que la propia estructura organizativa de la ONU deba (aunque en realidad no se quiera) ser reformada en sentido democrático. En todo caso, quizá sea pertinente recordar hoy que ya en su momento Thomas Paine (1984: 192) sostuvo que "una constitución es algo que antecede al gobierno, y un gobierno no es más que la criatura de una constitución. La constitución de un país no es el acto de su gobierno, sino del pueblo que constituye su gobierno". Avancemos pues hacia una tal constitución e incorporemos a ella -como también defendía Paine, al igual que Thomas Jefferson- lo que hoy no sería otra cosa que una suerte de Declaración Universal de Derechos Humanos.

Parece pues, al menos eso creo, que las mejores posibilidades para una efectiva participación política ciudadana han de remitirse, de nuevo, al ámbito del Estado y sus respectivas comunidades subestatales. De ahí que, dentro de los límites de aquellos principios y normas generales cosmopolitas, sea en el interior de estas entidades donde debe igualmente proseguir la lucha por los derechos que, en realidad, habrá de ser una lucha por la democracia y la justicia social. Y respecto de estos últimos ámbitos -estatal, regional o local- cabe igualmente señalar que existen alternativas a los ya comentados problemas de la democracia liberal. El catálogo de ideas a este respecto -comenzando por las ya sugeridas a principios del siglo XX por Kelsen- es igualmente extenso y no es cuestión de detenerme en ello cuando debería ya concluir este trabajo. Me limitaré por tanto a indicar que del diagnóstico anteriormente realizado cabe extraer no pocas terapias al respecto. Claro que nuestras terapias se orientan hacia una suerte de recuperación y actualización del ya citado enfoque participativo. Desde tal punto de vista, las alternativas pasan por hacer más representativa, participativa y social a la democracia liberal. Se trataría, en suma, de ampliar la dimensión social y radicalizar la dimensión participativa de la propia democracia liberal. Ciertamente, para qué engañarnos, los obstáculos son realmente importantes, entre otras cosas porque, al igual que ocurre en el ámbito cosmopolita y en el europeo, quienes deberían promover tales transformaciones -las potencias hegemónicas en un caso y los partidos mayoritarios en el otro- no parecen dispuestos a ello. Parece pues que, en resumidas cuentas, esos avances dependen en buena medida de la presión y movilización que la opinión pública, la sociedad civil y las fuerzas políticas interesadas en tal avance sean capaces de poner en juego. 


\section{Bibliografía}

Acinas, J.C. (2009), “Videopolítica y democracia”, Laguna. Revista de Filosofía, 25: 109-128.

Archibugi, D. (2005), "La democracia cosmopolita: una respuesta a las críticas”, Centro de Investigaciones para la Paz.

Bachrach, P. (1973), Crítica de la teoría elitista de la democracia, Buenos Aires, Amorrortu.

Bell, D. (1986), El advenimiento de la sociedad post-industrial, Madrid, Alianza.

Bell, D. (1977), Las contradicciones culturales del capitalismo, Madrid, Alianza.

Bobbio, N. (1984), «Le promesse non mantenute della democrazia», Mondoperaio, 5: $100-105$

Bobbio, N. (1985), El futuro de la democracia, Barcelona, Plaza \& Janés.

Bobbio, N. (1986), ¿Qué socialismo?, Barcelona, Plaza \& Janés.

Brittan, S. (1975), “The Economic Contradictions of Democracy”, British Journal of Political Science, 5: 129-160.

Bryce, J. (1921) Modern Democracies, vol. 1, New York, Macmillan, 1921.

Buchanan, J. Y Wagner, R. (1977), Democracy in Deficit. The Political Legacy of Lord Keynes, New York, Academic Press, 1977.

Crozier, M., Huntington, S.P. Y Watanuki, J. (1975), The Crisis of Democracy. Report on the Governability of Democracies to the Trilateral Commission, New York, New York University Press

Dahl, R. (199), La democracia. Una guía para los ciudadanos, Madrid, Taurus.

Dahl, R. (2004), "Can International Organizations Be Democratic? A Skeptical View”, en David Held-Anthony Mcgrew, eds. (2004), The Global Transformation Reader. An Introduction to the Globalization Debate, Oxford, Polity Press.

Diamond, L. (2008), The Spirit of Democracy: The Struggle to Build Free Societies Throughout the World, New York, Times Books.

Ferrajoli, L. (2011a), Principia Iuris. Teoría del derecho y la democracia. 2. Teoría de la democracia, Madrid, Trotta.

Ferrajoli, L. (2011b), Poderes salvajes. La crisis de la democracia constitucional, Madrid, Trotta.

Freedom House, (2000), "Democracy's Century: A Survey of Global Political Change in the 20th Century", Nueva York, Freedom House.

Fukuyama, F. (1990), “¿El final de la historia?”, Estudios Públicos, 37: 5-31.

Garzón Valdés, E. (2003), “Algunas consideraciones sobre globalización y democracia”, Quórum: Revista de pensamiento iberoamericano, 7: 22-31.

Habermas, J., (2000), La constelación posnacional. Ensayos políticos, Barcelona, Paidós.

Habermas, J. (2004), Tiempo de transiciones, Madrid, Trotta.

Hayek, F, von, (1982), El orden político en una sociedad libre, Madrid, Unión Editorial.

Held, D. (1997), La democracia y el orden global, Barcelona, Paidós. 
Held, D. (2001), Modelos de democracia, Madrid, Alianza.

Held, D. (2011), Cosmopolitismo. Ideales y realidades, Madrid, Alianza.

Hermet, G. (2008), El invierno de la democracia. Auge y decadencia del gobierno del pueblo, Barcelona, Los libros del lince.

Hobsbawn, E. (1994), The Age of Extremes. The Short Twentieth Century: 19141991, London, Michael Joseph.

Huntington, S. P. (1994), La tercera ola. La democratización a finales del siglo XX, Barcelona, Paidós.

Inglehart, R. (1977), The Silent Revolution: Changing Values and Political Styles among Western Publics, Princeton, Princeton University Press.

Inglehart, R. (1991), El cambio cultural en las sociedades industriales avanzadas, Madrid, Siglo XXI.

Katz, R. Y Mair, P. (2004), "El partido cartel. La transformación de los modelos de partidos y de la democracia de partidos", Zona Abierta, 108/109: 9-39.

Keane, J. (1996), Reflections on Violence, London, Verso.

Kelsen, H. (1977), Esencia y valor de la democracia, Madrid, Labor.

Kelsen, H. (1988), Escritos sobre la democracia y el socialismo, Madrid, Debate.

Kelsen, H. (1983), Teoría general del Estado, México, Editora Nacional.

Kirchheimer, O. (1954), "Notes on the Political Scene in Western Germany», World Politics, 6, 3: 306-321.

Kirchheimer, O. (1980), «El camino hacia el partido de todo el mundo», en Kurt Lenk Y Franz Neumann (eds.), Teoría y sociología. Críticas de los partidos políticos, Barcelona, Anagrama: 328-347.

Laski, H. (1935), Democracy in crisis, The University of North Carolina Press.

Macpherson, C.B. (1987), La democracia liberal y su época, Madrid, Alianza.

Máiz, R., ed. (2001), Construcción de Europa, Democracia y Globalización, vol. II, Santiago de Compostela, Univ. Santiago de Compostela.

Manin, B. (1998), Los principios del gobierno representativo, Madrid, Alianza.

Mann, M. (2005), The Dark Side of Democracy: Explaining Ethnic Cleansing, New York, Cambridge University Press.

Montero, J.R. Y Morlino, L. (1999), "Legitimidad y democracia en el Sur de Europa", REIS, 64: 7-40.

Montero, J.R., Gunther. R. y Torcal, M. (1999), "Legitimidad, descontento y desafección. El caso español", Estudios Públicos, 74:.107-149.

Muguerza, J. (2004), “Cosmopolitismo y derechos humanos”, en Vicente Serrano (coord.), Ética y globalización: cosmopolitismo, responsabilidad y diferencia en un mundo global, Madrid, Biblioteca Nueva.

O’Donnell, G. (1997), Contrapuntos: ensayos escogidos sobre autoritarismo y democratización, Buenos Aires, Paidós.

Offe, C. (1988), Partidos políticos y nuevos movimientos sociales, Madrid, Sistema.

Offe, C. (2001), “¿La desafección política como consecuencia de las prácticas institucionales? Algunas consideraciones neotocquevilleanas”, en Ramón Máiz, ed., (2001).

Paine, TH. (1984), Los derechos del hombre, Madrid, Alianza 
Pateman, C. (2000), Participation and Democratic Theory, Cambridge University Press.

Pareto, V. (1985), La transformación de la democracia, Madrid, EDERSA.

Peña, J. (2010), La ciudad sin murallas. Política en clave cosmopolita, El Viejo Topo.

Quesada, F. (2008), Sendas de democracia. Entre la violencia y la globalización. Madrid, Trotta.

Rodríguez Guerra, J., (2001), Capitalismo flexible y Estado de bienestar, Granada, Comares.

Rodríguez Guerra, R. (1998), El liberalismo conservador contemporáneo, La Laguna, Univ. de La Laguna.

Rodríguez Guerra, R. (1998a), "Pluralismo y democracia. La filosofía política ante los retos del pluralismo social”, en F. Quesada, ed., La filosofía política en perspectiva, Barcelona, Anthropos: 69-97.

Rodríguez Guerra, R. (2011), "El triunfo de la democracia liberal. Crítica de las concepciones procedimentales de la democracia", Rivista elettronica della Società Italiana di Filosofia Politica, 30 settembre 2011 (http://eprints.sifp.it/259/).

Sartori, G. (1991), "Una nueva reflexión sobre la democracia, las malas formas de gobierno y la mala política", RICS, 129: 459-485.

Sartori, G. (1993), La democracia después del comunismo, Madrid, Alianza, 1993.

Schmitt, C. (1990), Sobre el parlamentarismo, Madrid, Tecnos.

Sinova, J. Y Tusell, J. (1997), La crisis de la democracia en España, Madrid, Espasa Calpe.

Tocqueville. A. de (1963), La democracia en América, México, FCE.

Torcal, M. (2001), "La desafección democrática en las nuevas democracias: sus orígenes y consecuencias”, en Ramón Máiz, ed. (2001): 1165-1207.

Trilling, L. (1965), Beyond culture. Essays on Literature and Learning, London, Penguin Books.

Weber, M. (1991), Escritos Políticos, Madrid, Alianza.

Weber, M. (1986), El científico y el político, Madrid, Alianza.

Weber, M. (1984) Economía y sociedad. Esbozo de sociología comprensiva, MéxiCo, FCE.

Wigell, M. (2008), "Mapping «Hybrid Regimes»: Regime Types and Concepts in Comparative Politics", Democratization, 15, 2: 230-250.

Williamson, J., "What Washington Means by Policy Reform", en John Williamson, ed., Latin American Adjustment: How Much Has Happened?, Washington, Institute for International Economics, 1990, pp. 5-20.

Wolin, SH. (2008), Democracia S.A. La democracia dirigida y el fantasma del totalitarismo, Barcelona Katz.

Zolo, D. (1984), Cosmópolis. Perspectivas y riesgos de un gobierno mundial, Barcelona, Paidós. 